\title{
ON THE RUN: A REVIEW OF DELUSIONAL MISIDENTIFICATION SYNDROMES
}

\author{
R. Laia ${ }^{1}$, B. Lourenço ${ }^{1}$, A. Nobre ${ }^{1}$. \\ ${ }^{1}$ Centro Hospitalar Psiquiátrico de Lisboa, Clínica 5, Lisboa, Portugal
}

\section{CLINICAL CASE:}

Male, 41 y.o., unemployed and homeless. In Portugal since one month before his hospitalization, on transit. Irrelevant personal background.

Brought to the ER, after being arrested with confused speech and psychomotor agitation, without identification. The patient claimed to be F.H., an American citizen and FBI agent. Through Immigration Service, he was identified as M.C., a Hungarian citizen, and the US Embassy denied him being either an American citizen or FBI agent. Upon mental status examination, the patient presented delusional ideas of identity and persecution. He denied acoustic-verbal hallucinations. There were no further changes on examination or imaging or blood tests.

Compulsory hospitalization was performed. During hospitalization, a systemic identity delirium with internal logic was observed:

- He said that his family was from the USA, of German and Native American origin, but his parents have passed away and he was adopted as a child by a Hungarian family, that he disliked, reporting abusive treatment.

- Allegedly, when he was 22 y.o. he received a letter from the US government informing him that he was an American citizen and recruiting him as an FBI agent. During hospitalization, he provided several official phone numbers and addresses of the FBI and US government, and attempted to contact all of them for his identity to be confirmed and for them to rescue him.

- Claimed to have been in Hungary lately to dismantle a human trafficking network, having found out sensitive information about the network, which was the reason for him to fled Hungary, crossing Europe to Portugal, planning to return to the US. Since then, he had been living on the street for 20 months, also claiming that his wife had been murdered a year earlier in France.

- During his stay in Lisbon, he was convinced that strangers with a Slavic appearance he saw on the street were his pursuers.

In the course of hospitalization, Clozapine was started with some progressive clinical stabilization, but he maintained the identity delirium, although with less dynamism. At the time of discharge, the patient accepted and performed an antipsychotic depot of haloperidol and was referred to the outpatient clinic of the hospital, where he never attended.

\section{METHODS}

Clinical case description and a non-systematic review through research in PubMed conducted with the expressions: "delusional misidentification syndromes". A short literature review of the theme was performed.

\section{RESULTS}

Classically, the Delusional Misidentification Syndromes (DMS) are composed of four well described and established subtypes:

Capgras Syndrome: a belief that someone known to him (eg: a relative) has been replaced by a double, that is, someone who has acquired the physical characteristics of the known person but not their psychological characteristics or personality.

Fregoli Syndrome: the patient thinks that unknown people are his acquaintances, but that they are disguised. That is, despite recognizing the physical differences, the patient identifies the psychological identity of an acquaintance in an unknown person.

Intermetamorphosis Syndrome: the patient believes that they can see others change into someone else in both external appearance and internal personality.

Subjective Doubles Syndrome: the patient thinks that he has one or more doubles or Doppelgängers, which have his exact same appearance but are psychologically different from himself, that are leading lives of their own.

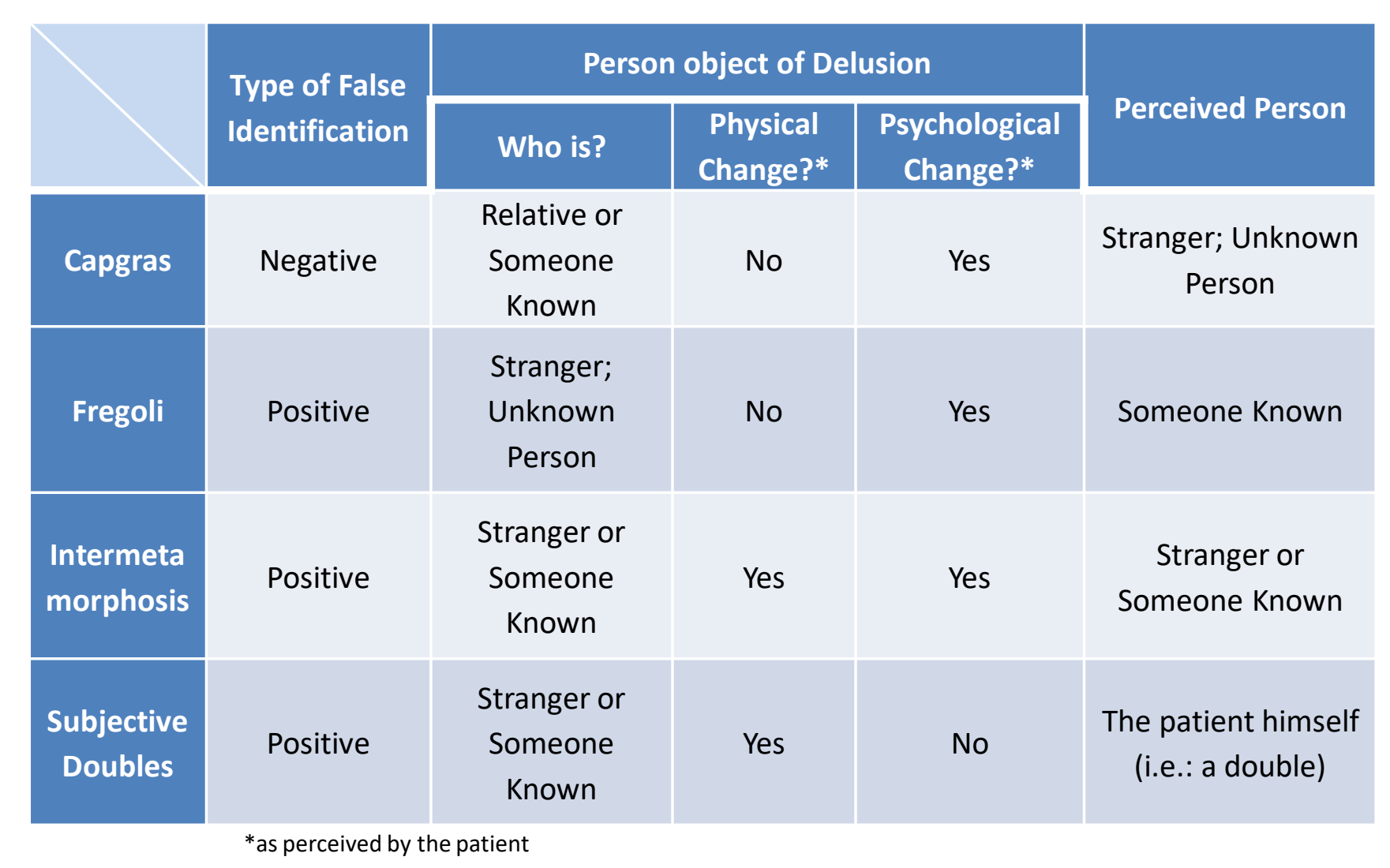

Additionally, other subtypes or different forms of presentation of DMS have been proposed and named. These include, for example:

- "Reverse" Subjective Doubles: a belief in psychological but not physical changes in his identity;

- "Reverse" Intermetamorphosis: a belief in psychological and physical changes in his identity

- "Reverse" Frégoli: a belief in physical but not psychological changes in his identity

- "Reverse" Capgras: belief in the self as a psychological impostor, inhabiting a body which the patient does not recognize as his own.

Although not defined as a DMS, because it is not assumed as part of a delusion but as a neurological condition, we should also mention Prosopagnosia, a neurocognitive disorder characterized as inability to recognize familiar faces, but not objects, which is closely related to Capgras Syndrome.

Also, it's worth mentioning other phenomena of misidentification closely related to DMS (which are defined as delusional beliefs that involve misidentifying people, places, or objects), such as Reduplicative Paramnesia (misidentification of a place or location) and Déjà vu and Jamais $\mathbf{V u}$ (misidentification of time and/or experiences).

\section{DISCUSSION AND CONCLUSION:}

Attending to the main delusion of the patient, in which he believes to be another person, we see that none of the four classical DMS applies to the case. Nevertheless, according to the definition of DMS and considering the other proposed subtypes, we can argue that the patient has a DMS and that somehow portrays the "Reverse Subjective Doubles" DMS subtype, as he never references any change in his appearance, but is rather convinced of being someone else, predominantly in socio-cultural aspects (name, citizenship, job and family), but also psychologically.

Additionally, the patient also described perceptions compatible with Fregoli Syndrome: he was convinced that Slavic people he saw on the street were some of the Eastern-Europe criminals he had investigated. This probably configures a Fregoli Syndrome, because he identifies people whom he most likely never met as the criminals he believes to have investigated, although based on a understandable physical resemblance with the stalkers of his delusion.

\section{SOURCES:}

Ellis HD, Luauté JP, RetterstøI N: Delusional misidentification syndromes. Psychopathology. 1994;27:117-20.

de Pauw KW: Delusional misidentification: plea for an agreed terminology and classification. Psychopathology. 1994;27:123-9. 